\title{
MicroRNA-16/VEGFR2/p38/NF-кB signaling pathway regulates cell growth of human pituitary neoplasms
}

\author{
BIN LU ${ }^{1}$, GE-LING LIU ${ }^{2}$, FANG YU ${ }^{2}$, WEI-JUAN LI ${ }^{2}$, XIU-XIU XIANG ${ }^{2}$ and HONG-ZHEN XIAO ${ }^{2}$ \\ Departments of ${ }^{1}$ Neurosurgery and ${ }^{2}$ Endocrinology, Tangshan Gongren Hospital \\ Affiliated to Hebei Medical University, Tangshan, Hebei 063000, P.R. China
}

Received March 21, 2017; Accepted January 4, 2018

DOI: $10.3892 /$ or.2018.6227

\begin{abstract}
The association of microRNA (miRNA) with tumor has gradually become an active medical research field, since its discovery in 1993. The aim of the present study was to clarify how microRNA-16 expression affects the proliferation and survival of pituitary tumor, revealing its potential mechanism. MicroRNA-16 expression of pituitary tumor patients was observably declined, compared with the normal group. A high expression of microRNA-16 showed longer survival in pituitary tumor patients, compared to a low expression of microRNA-16 in pituitary tumor patients. MicroRNA-16 upregulation effectively decreased cell proliferation and induced apoptosis in HP75 cells. MicroRNA-16 overexpression effectively induced p27, Bax protein expression and caspase-3/8 activities, and

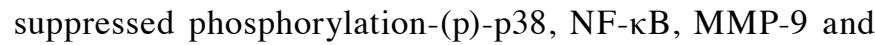
VEGFR2 protein expression in HP75 cells. After VEGFR2 suppression, the effects of microRNA-16 overexpression on cell proliferation and apoptosis were significantly inhibited in HP75 cells. Moreover, the effects of microRNA-16 overexpression on $\mathrm{p} 27$, Bax protein expression and caspase-3/8 activities were significantly decreased in HP75 cells after p38 suppression. VEGFR2 or $\mathrm{NF}-\kappa \mathrm{B}$ suppression reduced the effects of microRNA-16 overexpression on p-p38, NF- $\kappa$, MMP-9 and VEGFR2 protein expression inhibition in HP75 cells. Our results suggest that microRNA-16 expression affects the proliferation and angiogenesis of pituitary cancer through the VEGFR2/p38/NF- $\mathrm{B}$ signaling pathway.
\end{abstract}

\section{Introduction}

Pituitary tumor is a common neuroendocrine system tumor, the morbidity of which accounts for $10-15 \%$ of all central nervous system tumors. Moreover, the morbidity increases annually, as is shown in epidemiological investigations (1).

Correspondence to: Dr Hong-Zhen Xiao, Department of Endocrinology, Tangshan Gongren Hospital Affiliated to Hebei Medical University, 27 Lubei District Culture Road, Tangshan, Hebei 063000, P.R. China

E-mail: yuannhbhpc@163.com

Key words: microRNA-16, pituitary neoplasms, VEGFR2, NF-кB, p38
A majority of pituitary tumors are benign tumors that grow slowly, with no typical early symptoms in clinic. However, a small number of these tumors can induce certain central nervous system symptoms since the excessive growth has compressed the intracranial structures (2). Furthermore, some tumors belong to functional pituitary adenomas, which cause endocrine function disorders as a result of the abnormal secretion of hormones. Consequently, this has led to numerous complications (3). Early tumor diagnosis is of vital importance to improve prognosis for cancer patients, while the early diagnosis of pituitary tumor, not only improves patient quality of life, but can also effectively prolong the life of patients (4).

miRNA generally acts on various types of oncogenes (including proto-oncogenes and tumor suppressor genes) through direct or indirect pathways, and thereby participates in tumor pathogenesis. It is indicated in current research that, $\sim 50 \%$ of miRNAs are related to tumor pathogenesis. Such miRNAs, which are located in tumor-associated fragile sites or particular tumor growth-associated genome domains, have dual identities (oncogenes or tumor suppressor genes) (5). Cancer miRNAs possess certain properties of oncogenes, which can specifically bind with the mRNA of tumor suppressor genes, and inhibit or degrade the expression of tumor suppressor genes. It can lead to silencing of targeted oncogenes, and thus indirectly promote growth or genesis of some tumors. In addition, such miRNAs are mostly excessively expressed in tumors, which means that they have elevated expression levels in the event of tumor genesis. In other words, their expression levels are upregulated in the event of tumor genesis. Anticancer miRNAs can specifically bind with cancer mRNA, and inhibit or degrade the expression of oncogenes (6). Therefore, they can inhibit transcription of targeted oncogenes and eventually inhibit tumor growth or genesis. Different from the former, the expression levels of such miRNAs are reduced (6). The discovery of cancer miRNA and anticancer miRNA has led to medical workers investigating the association of miRNA with tumor (7). This provides insight into the investigation of the specific pathogenesis, diagnosis and treatment of pituitary tumor (7).

Pituitary tumor is a kind of benign tumor that does not metastasize under general conditions, but $\sim 30 \%$ invades the surrounding structures (8). Such tumors can hardly be radically treated, and total resection is difficult, leading to a high postoperative recurrence rate. CD147, which is also referred 
to as the extracellular matrix metalloproteinase inducer (EMMPRIN), is a cell surface adhesion molecule. It plays a role in stimulating the production of matrix metalloproteinases (MMPs) and affects tumor invasion and metastasis. In the subfamily of MMPs, MMP-9 is most closely associated with the invasion of pituitary tumor (9). Tumor angiogenesis is closely related to tumor growth and metastasis. Vascular endothelial growth factor (VEGF2) is one of the pro-angiogenic factors known currently to have the strongest effect, and it plays an important role in tumor formation (10).

From the point of view of cell apoptosis, out of control growth and excessive proliferation of tumor cells occurs owing to the fact that that death cells cannot be eliminated normally since the tumor apoptotic mechanism is inhibited (11). p38MAPK pathway is an important pathway involved in the initiation of cell apoptosis, which can exert biological effects after being activated by the extracellular stimulus, thus regulating various cell functions (12). It mainly mediates physiological functions such as differentiation, proliferation and apoptosis (11). Therefore, clarifying its mechanism of action during tumor genesis, development and treatment outcome is necessary.

$\mathrm{NF}-\mathrm{\kappa B}$ is a family of transcription factors existing in eukaryotic cells with extensive distribution and multiple effects. It is one of the most important intracellular nuclear transcription factors that participate in the expression and regulation of multiple genes, which is the symbol of activated cells (13). $\mathrm{NF}-\kappa \mathrm{B}$ is verified in research to participate in inflammatory reaction and immune response of the body. In addition, it is involved in pathophysiological processes, such as cell proliferation, differentiation and apoptosis (14). Furthermore, the nuclear factor NF- $\kappa \mathrm{B}$ is associated with tumor invasion and metastasis. NF- $\mathrm{kB}$ controls DNA transcription and the binding of the fixed nucleotide sequence in the promoter region of the gene. It is involved in pathophysiological processes including immune reaction, inflammatory reaction, and cell apoptosis. Thus, it promotes a series of important vital activities, such as cell proliferation and differentiation, tumor formation and metastasis (15). The aim of the present study was to clarify how microRNA-16 expression affects the proliferation and survival of pituitary tumor and reveal its potential mechanism.

\section{Materials and methods}

Human tissue samples and reverse transcriptase-quantitative polymerase chain reaction ( $R T-q P C R)$. Thirty-six patients with pituitary tumor and 8 healthy volunteers were selected, and the peripheral blood was collected and centrifuged at $2,000 \mathrm{x} \mathrm{g}$ for $20 \mathrm{~min}$. Serum was collected and saved at $-80^{\circ} \mathrm{C}$. Total RNA was extracted using RNAiso Plus according to the manufacturer's instructions (Takara, Japan). cDNA was reverse-transcribed using the One Step PrimeScript ${ }^{\circledR}$ miRNA cDNA Synthesis kit (Takara) and PrimeScript ${ }^{\circledR}$ RT Master Mix Perfect Real Time (Takara), according to the manufacturer's instructions. RT-qPCR reactions were performed using SYBR $^{\circledR}$ Premix Ex Taq ${ }^{\mathrm{TM}}$ II (Perfect Real Time; Takara) by an Applied Biosystems 7500 Fast Real-Time PCR system.

Written informed consent was obtained from the patients. The study was approved by the Ethics Committee of Tangshan Gonren Hospital, Tangshan, China.

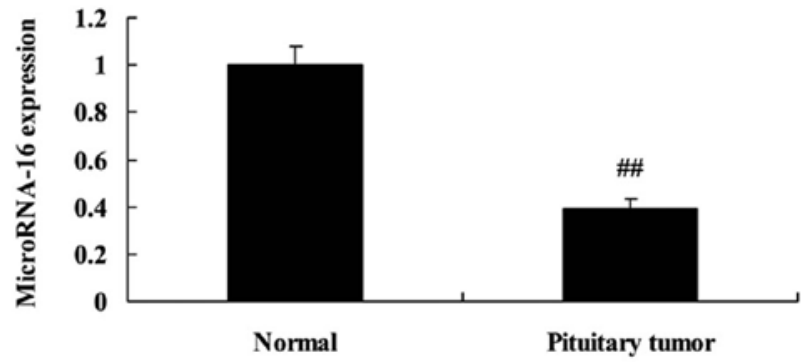

Figure 1. MicroRNA-16 expression of pituitary tumor patients. ${ }^{\# \#} \mathrm{P}<0.01$ versus normal group.

Cells and overexpression of miR-16. Human pituitary cancer HP75 cells were incubated with low-glucose Dulbecco's modified Eagle's medium complete medium (Invitrogen, Carlsbad, CA, USA) containing $10 \%$ fetal calf serum (FCS, Harlan, Madison, WI, USA) in a humidified chamber with $5 \% \mathrm{CO}_{2}$ at $37^{\circ} \mathrm{C}$. HP75 cells were seeded in 6 -well plates ( $70 \%$ confluent), and $50 \mathrm{nM}$ of miR-16 mimics (miR-16) and negative control RNA mimics (Ribobio, Guangzhou, China) were transfected using Lipofectamine 3000 (Invitrogen, Guangzhou, China). HP75 cells were treated with $5 \mu \mathrm{M}$ of PDTC (NF- $\kappa B$ inhibitor) for $24 \mathrm{~h}$ after transfection.

MTT proliferation assay. HP75 cells were seeded in a 96-well plate after transfection for $48 \mathrm{~h}$. Then, MTT $(5 \mathrm{mg} / \mathrm{ml}$ in sodium chloride) was added to the cells for the last $2 \mathrm{~h}$ of incubation and cell viability was measured at $570 \mathrm{~nm}$ using a microplate reader (Tecan M1000, Invitrogen, Carlsbad, CA, USA) after being dissolved in DMSO.

Flow cytometry. The anticancer effect of dihydroartemisinin on apoptosis of tumor cells was examined using a FACSCalibur flow cytometer (BD Biosciences, San Jose, CA, USA). HP75 cells were seeded in a 6-well plate after transfection for $48 \mathrm{~h}$. After rinsing in PBS three times, HP75 cells were resuspended with Annexin V-FITC $(5 \mu$ l, KeyGen Biotech Co., Ltd.) in the dark for 30 min followed by PI dye ( $5 \mu \mathrm{l}$, KeyGen Biotech Co., Ltd., Jiangsu, China). Apoptosis rate of HP75 cells was measured by FACSCalibur flow cytometer (BD Biosciences).

Western blot assay. The anticancer effect of dihydroartemisinin on apoptosis of tumor cells was examined using a FACSCalibur flow cytometer (BD Biosciences). HP75 cells were seeded in a 6-well plate after transfection for $48 \mathrm{~h}$. The cells were then collected and lysed in Laemmli buffer to extract total proteins. Protein content was measured using the bicinchoninic acid protein assay kit method (Beyotime Institute of Biotechnology, Jiangsu, China). Proteins (50 $\mu \mathrm{g}$ ) were separated by $10 \%$ SDS-PAGE and transferred onto PVDF membrane $(0.45 \mathrm{~mm}$, Millipore, Billerica, MA, USA). The membrane was blocked with 5\% non-fat milk in TBST for $2 \mathrm{~h}$ and incubated overnight with the corresponding primary antibodies: anti-p27 (sc-528, 1:500, Santa Cruz Biotechnology), anti-Bax (sc-6236, 1:500, Santa Cruz Biotechnology), anti-NF-кB (sc-7151, 1:500, Santa Cruz Biotechnology), anti-MMP-9 (sc-10737, 1:500, Santa Cruz Biotechnology), anti-VEGFR2 (9698, 1:2,000, Cell Signaling Technology, Inc.), anti-p53 (2527, 1:2,000, Cell Signaling 
A

High expression of microRNA-16

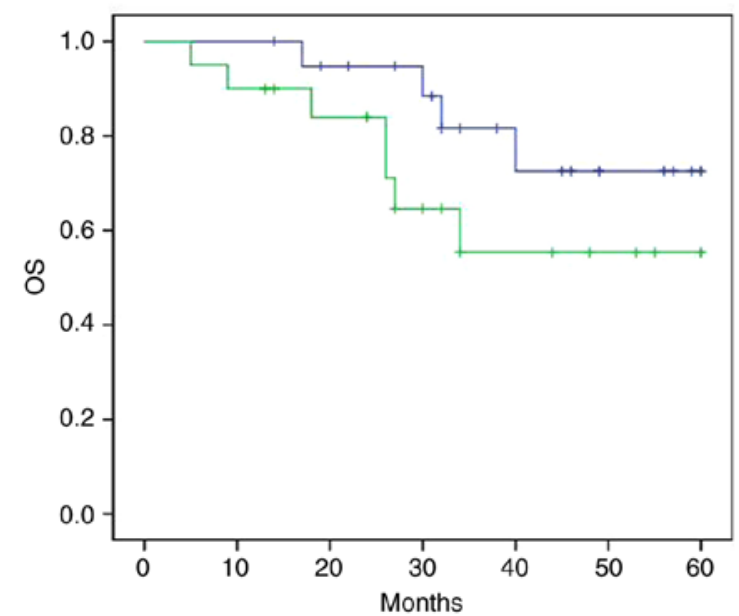

B

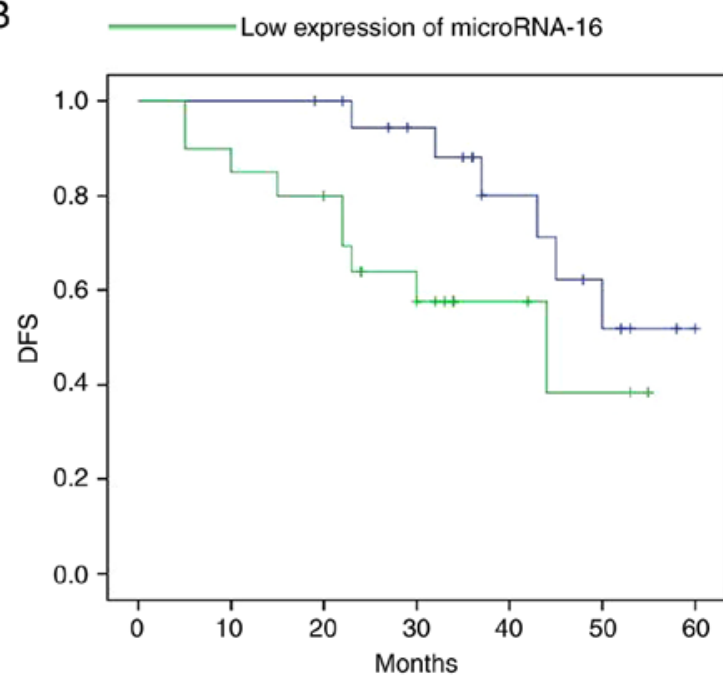

Figure 2. Survival rate of pituitary tumor patients with microRNA-16 expression. (A) Overall survival (OS) and (B) disease-free survival (DFS) of pituitary tumor patients with microRNA-16 expression. Patients with pituitary tumor $(\mathrm{n}=36)$ and healthy volunteers $(\mathrm{n}=8)$. ${ }^{\# \#} \mathrm{P}<0.01$ versus normal group.
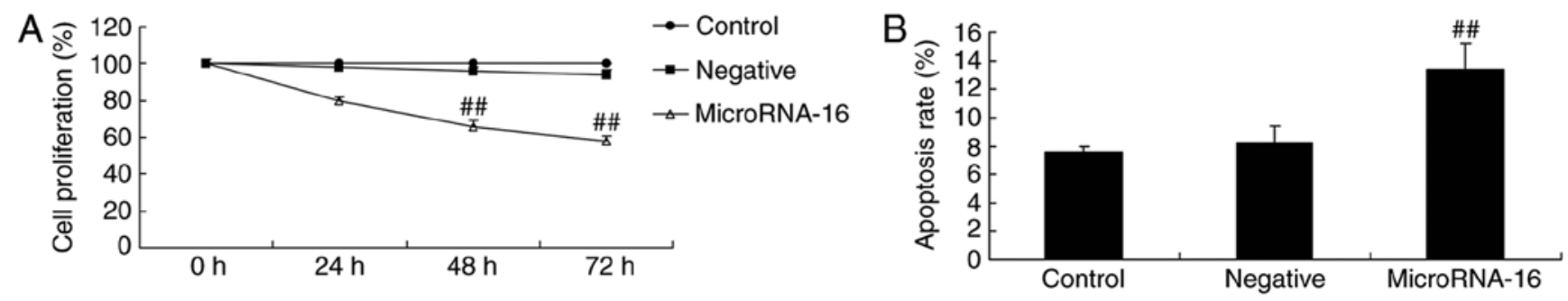

Figure 3. MicroRNA-16 upregulation affects cell proliferation and apoptosis of HP75 cells. MicroRNA-16 mimics affect (A) cell proliferation and (B) apoptosis of HP75 cells. Control, control group. Negative, negative control group. MicroRNA-16, microRNA-16 upregulation group. Repeat times (n=3). ${ }^{\# \#} \mathrm{P}<0.01$ versus normal group.

Technology, Inc.) and anti-GAPDH (sc-25778, 1:2,000, Santa Cruz Biotechnology) at $4^{\circ} \mathrm{C}$. Then, the membrane was incubated with secondary antibody (sc-2004, 1:5,000, Santa Cruz Biotechnology) at $37^{\circ} \mathrm{C}$ for $1 \mathrm{~h}$ and was determined with ImageJ software (open source, http://rsb.info.nih.gov/ij/index.html).

Caspase-3 and -9 activity assay. HP75 cells were seeded in a 6-well plate after transfection for $48 \mathrm{~h}$. The cells were then collected and lysed in Laemmli buffer for the extraction of total proteins. Protein content was measured using the bicinchoninic acid protein assay kit method (Beyotime Institute of Biotechnology). Proteins $(20 \mu \mathrm{g})$ were used to measure caspase-3 and -9 activity with Ac-DEVD- $p$ NA for caspase-3 or Ac-LEHD- $p$ NA for caspase-9. Caspase-3 and -9 activity was measured using a microplate reader (Tecan M1000) at $405 \mathrm{~nm}$.

Statistical analysis. Statistical significance was calculated employing analysis of variance (one-way ANOVA, Tukey's multiple comparison test). Data were presented as mean \pm standard deviation (SD). A statistical significance was defined as $\mathrm{P}<0.05$.

\section{Results}

MicroRNA-16 expression of pituitary tumor patients. Firstly, 36 patients with pituitary tumor and 8 healthy volunteers were selected, and serum was collected and used to analyze microRNA-16 expression of pituitary tumor patients. As shown in Fig. 1, microRNA-16 expression of pituitary tumor patients was observably declined, compared with the normal group. The differences were statistically significant $(\mathrm{P}<0.05)$.

Survival rate of pituitary tumor patients with microRNA-16 expression. The high expression of microRNA-16 shows longer survival (overall survival, OS and disease-free survival, DFS) in pituitary tumor patients, compared to a low expression microRNA-16 in pituitary tumor patients (Fig. 2).

MicroRNA-16 upregulation affects cell proliferation and apoptosis of HP75 cells. In order to predict the upstream microRNA-16 effects on cell proliferation and apoptosis of HP75 cells, miR-16 mimics and mimics-NC were transiently transfected into HP75 cells. microRNA-16 mimics decreased cell proliferation and induced apoptosis of HP75 cells in a dose-dependent manner, compared to the mimics-NC group (Fig. 3).

MicroRNA-16 upregulation affects caspase-3/8 activities in HP75 cells. To investigate the role of microRNA-16 in the regulation of caspase-3/8 activities of HP75 cells, caspase-3/8 activities were measured using caspase- 3 and -8 activity kits. Additionally, Fig. 4A shows that microRNA-16 mimics 

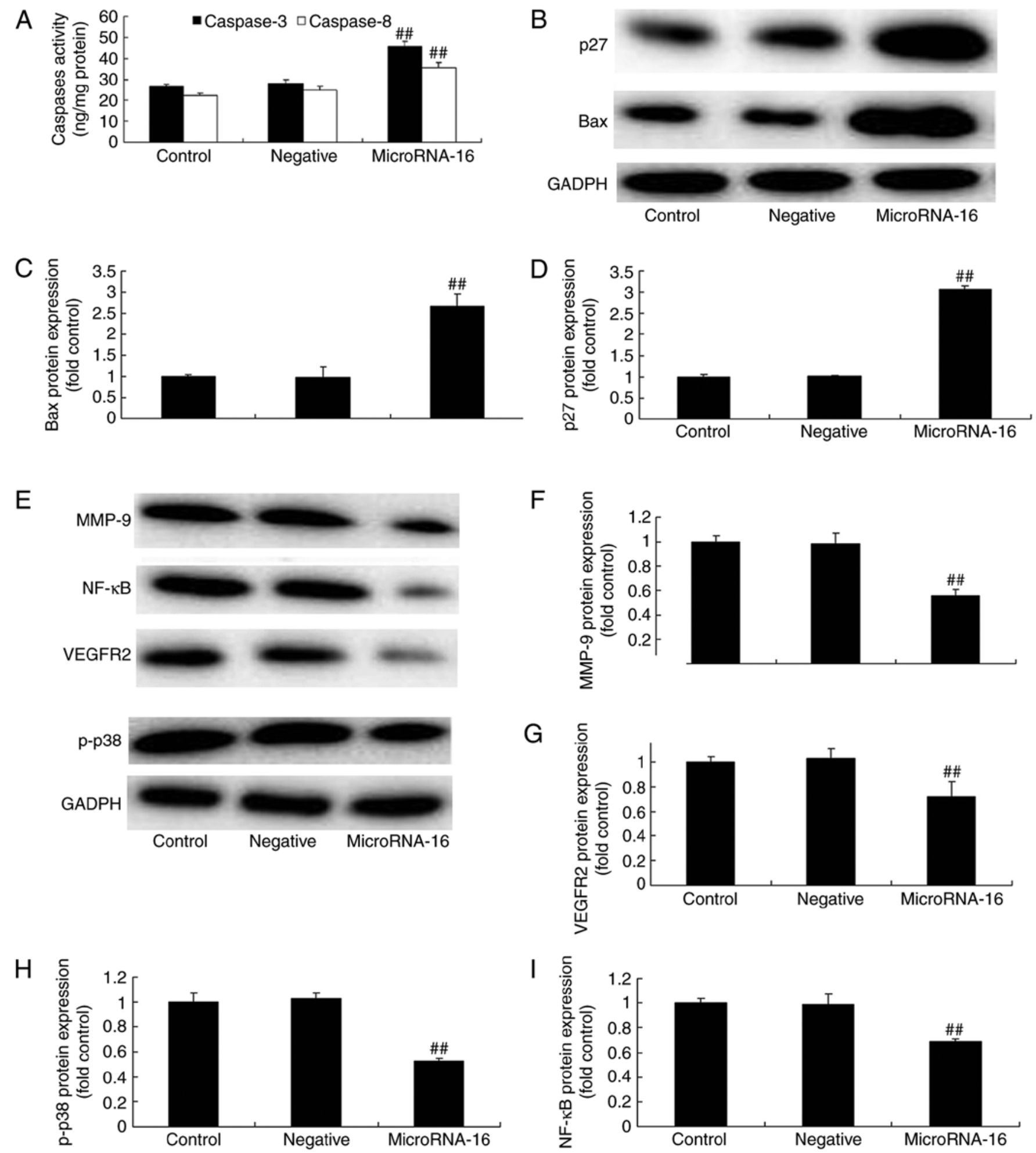

Figure 4. MicroRNA-16 upregulation affects caspase-3/8 activities, p27/Bax protein expression and p27 and Bax protein expression in HP75 cells. MicroRNA-16 upregulation affects (A) caspase-3/8 activities, (B) p27 and Bax protein expression using western blot analysis and statistical analysis of (C) Bax and (D) p27 protein expression, (E) p-p38MAPK, NF-кB, MMP-9 and VEGFR2 protein expression using western blot analysis and statistical analysis of (F) MMP-9, (G) VEGFR2, (H) p-p38MAPK and (I) NF-кB protein expression in HP75 cells. Control, control group. Negative, negative control group. MicroRNA-16, microRNA-16 upregulation group. Repeat times $(\mathrm{n}=3) .{ }^{\# \#} \mathrm{P}<0.01$ versus normal group.

effectively increased caspase-3/8 activities in HP75 cells, compared to the mimics-NC group.

MicroRNA-16 upregulation affects p27 and Bax protein expression in HP75 cell. To confirm the prediction of
microRNA-16 mechanism on pituitary tumor, we measured p27, Bax protein expression in HP75 cells. Our results indicated a significant increase of $\mathrm{p} 27$, Bax protein expression in HP75 cells after microRNA-16 upregulation, compared to the mimics-NC group (Fig. 4B-D). 


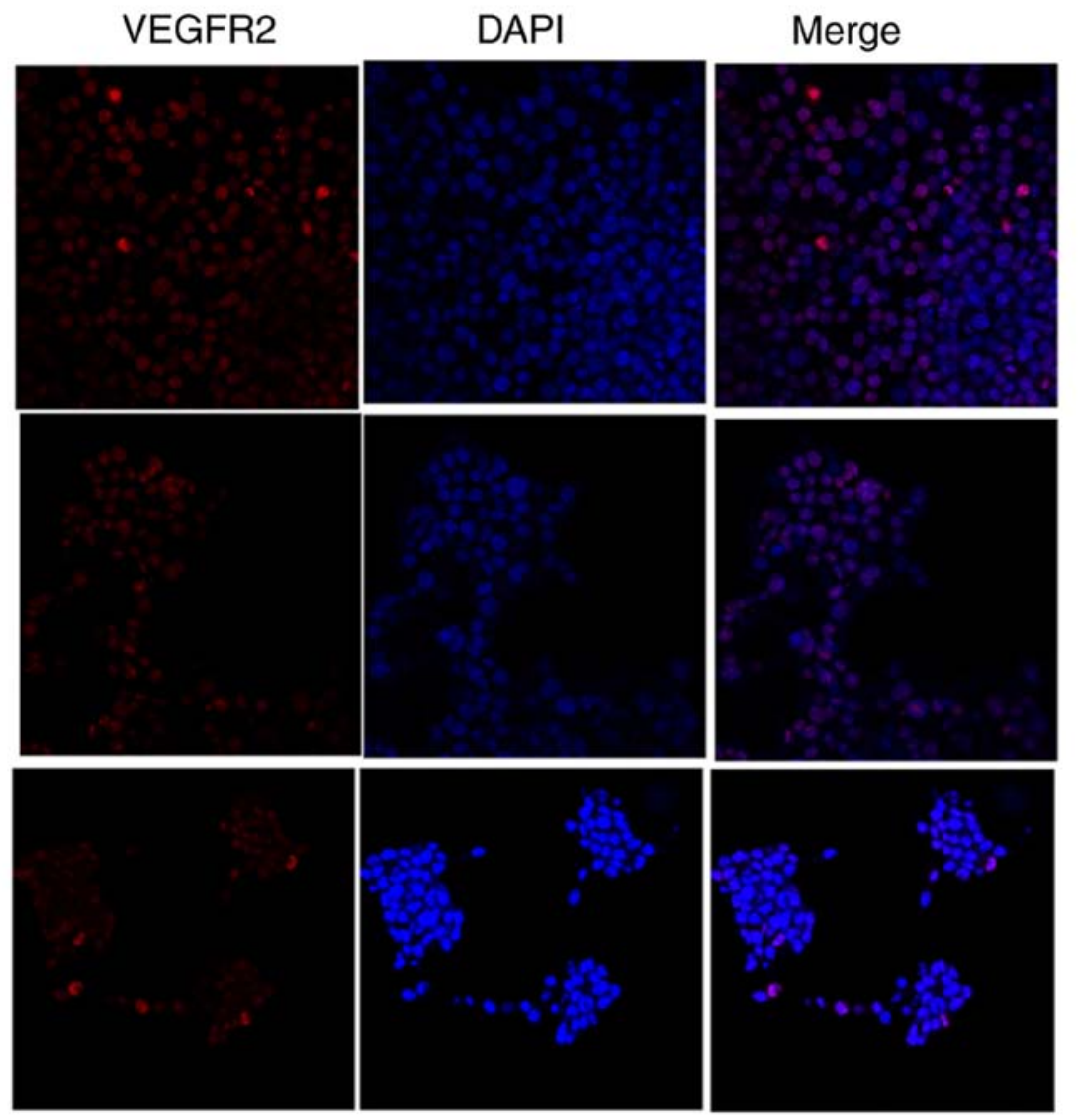

\section{Control}

Negative

MicroRNA-16

Figure 5. MicroRNA-16 upregulation reduces VEGFR2 protein expression in HP75 cells. Control, control group. Negative, negative control group. MicroRNA-16, microRNA-16 upregulation group. Repeat times $(n=3)$.

MicroRNA-16 upregulation affects p38MAPK, NF- $\kappa B$, MMP-9 and VEGFR2 protein expression in HP75 cells. To confirm the mechanism of microRNA-16 on pituitary tumor, we measured p-p38MAPK, NF- $\mathrm{B}, \mathrm{MMP}-9$ and VEGFR2 protein expression in HP75 cells. Our results indicated significant reduction of p-p38MAPK, NF- $\kappa$ B, MMP-9 and VEGFR2 protein expression in HP75 cells after microRNA-16 upregulation, compared to the mimics-NC group (Fig. 4E-I). We used immunohistochemistry to observe VEGFR2 protein expression in HP75 cells after microRNA-16 upregulation. MicroRNA-16 upregulation significantly suppressed VEGFR2 protein expression in HP75 cells, compared to the mimics-NC group (Fig. 4E-I).

Effects of microRNA-16 overexpression on p38MAPK, NF- $\kappa B$, MMP-9 and VEGFR2 protein expression in HP75 cells following VEGFR2 suppression. To study whether VEGFR2 participated in the effects of microRNA-16 overexpression on cell apoptosis of HP75 cells, $5 \mathrm{nM}$ of vandetanib (VEGFR2 inhibitor) was used in HP75 cells after microRNA-16 overexpression. VEGFR2 inhibitor significantly suppressed p-p38MAPK, NF- $\kappa$ B, MMP-9 and VEGFR2 protein expression of HP75 cells after microRNA-16 overexpression, compared to the microRNA-16 mimics group (Figs. 5 and 6A-E).

Effects of microRNA-16 overexpression on cell proliferation and apoptosis of HP75 cells following VEGFR2 suppression.
Our results indicated that VEGFR2 inhibitor significantly suppressed the effects of microRNA-16 overexpression on cell proliferation reduction and apoptosis induction in HP75 cells, compared to the microRNA-16 mimics group (Fig. 6F and G).

Effects of microRNA-16 overexpression on caspase-3/8 activities in HP75 cells following VEGFR2 suppression. To investigate whether VEGFR2 participated in the effects of microRNA-16 overexpression on caspase-3/8 activities in HP75 cells, caspase-3/8 activities were also measured. As shown in Fig. 6I-K, NF- $\mathrm{B}$ inhibitor significantly increased the effects of microRNA-16 overexpression on caspase-3/8 activities in HP75 cell, compared to the microRNA-16 mimics group (Fig. 6H).

Effects of microRNA-16 overexpression on p27 and Bax protein expression in HP75 cells following VEGFR2 suppression. After VEGFR2 suppression, we also observed p27 and Bax protein expression in HP75 cells following microRNA-16 overexpression. p27 and Bax protein expression in HP75 cells following microRNA-16 overexpression was higher than those of microRNA-16 mimics group (Fig. 6I-K).

Effects of microRNA-16 overexpression on $N F-\kappa B$, and MMP-9 protein expression in HP75 cells following $N F-\kappa B$ suppression. Next, we explored the function of $N F-\kappa B$ and the effects of microRNA-16 overexpression on NF- $\mathrm{NB}$, and MMP-9 protein expression in HP75 cells. As shown in Fig. 7A-C, NF- $\kappa$ B 
A
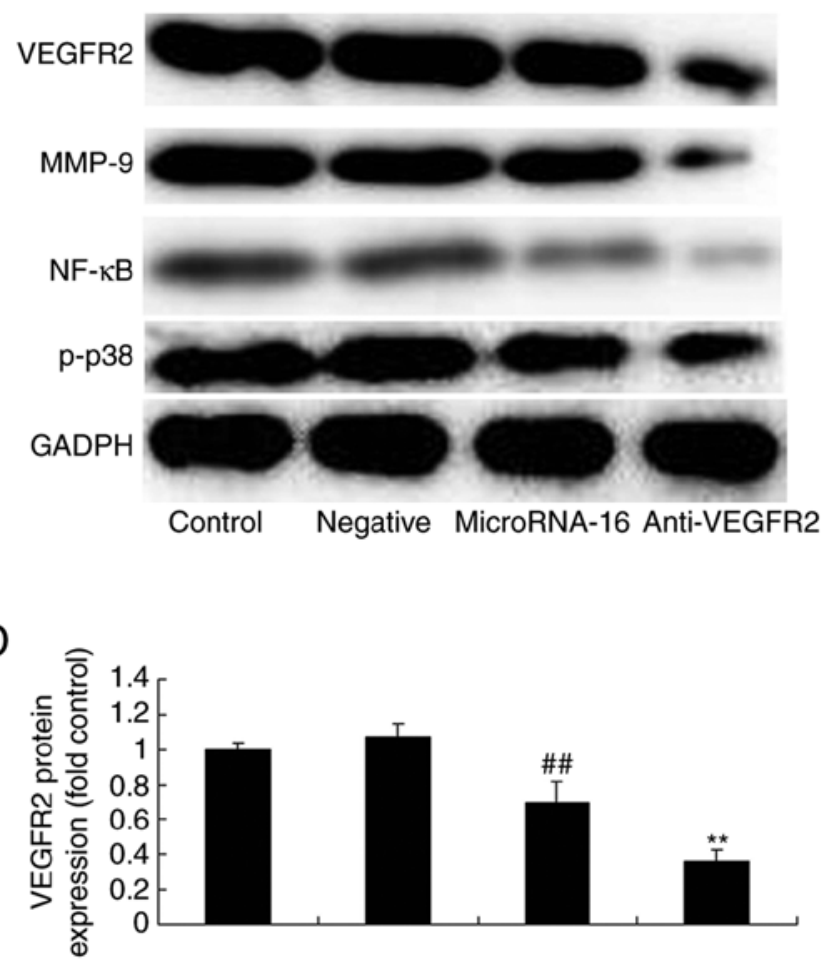

$\mathrm{F}$
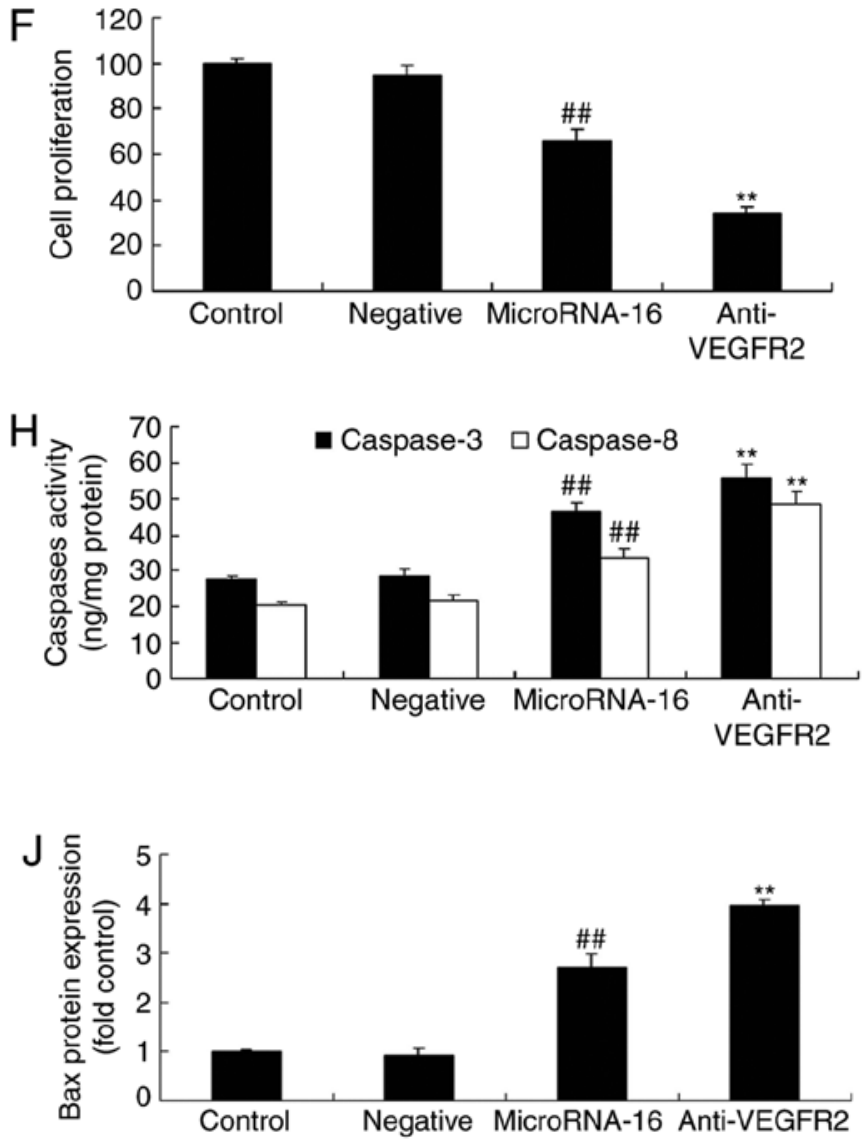

B

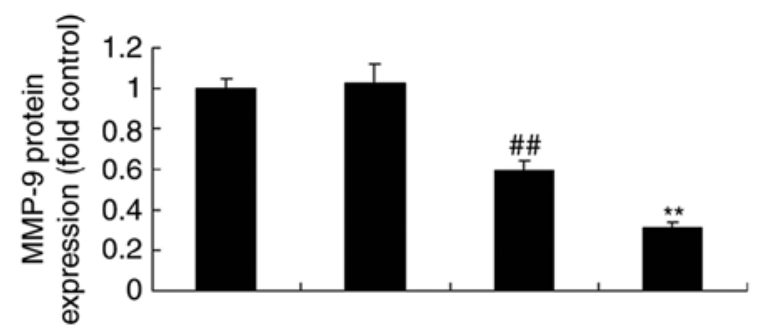

C

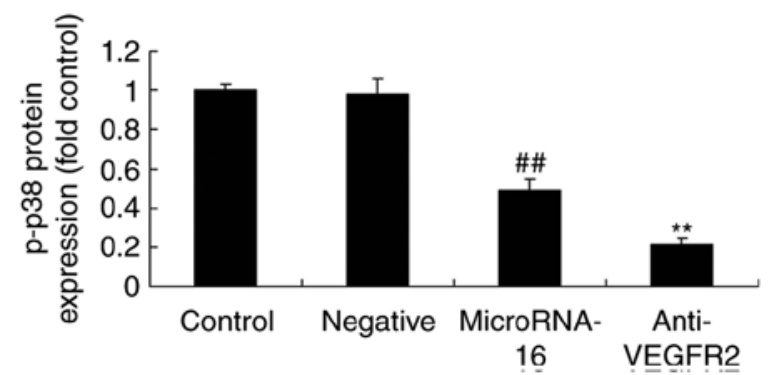

$E$
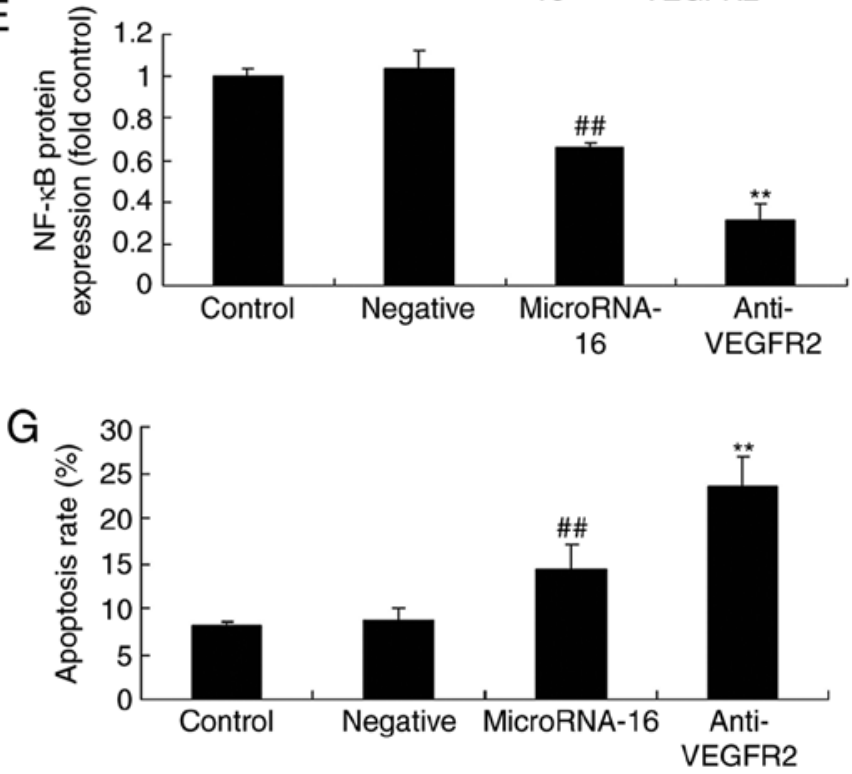

I
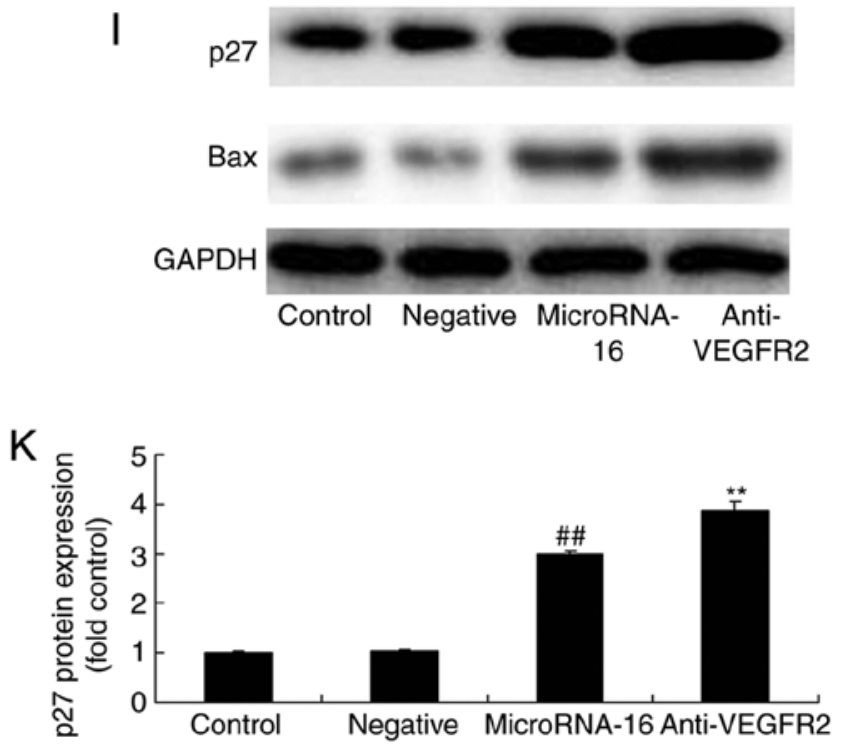

Figure 6. MicroRNA-16 upregulation affects p38MAPK/NF-кB/MMP-9/VEGFR2 protein expression, cell proliferation and apoptosis, caspase-3/8 activities, and p27/Bax protein expression in HP75 cells. MicroRNA-16 upregulation affects (A) p-p38MAPK, NF-kB, MMP-9 and VEGFR2 protein expression, determined using western blot analysis and statistical analysis of (B) MMP-9, (C) VEGFR2, (D) p-p38MAPK, and (E) NF-kB protein expression, (F) cell proliferation and (G) apoptosis, (H) caspase-3/8 activities, (I) p27 and Bax protein expression, determined using western blot analysis, and statistical analysis of (J) Bax, (K) p27 protein expression in HP75 cells. Control, control group. Negative, negative control group. MicroRNA-16, microRNA-16 upregulation group. Anti-VEGFR2, VEGFR2 inhibitor + microRNA-16 upregulation group. Repeat times $(\mathrm{n}=3) .{ }^{\# \#} \mathrm{P}<0.01$ versus normal group, ${ }^{* *} \mathrm{p}<0.01$ versus microRNA-16 upregulation group. 
A

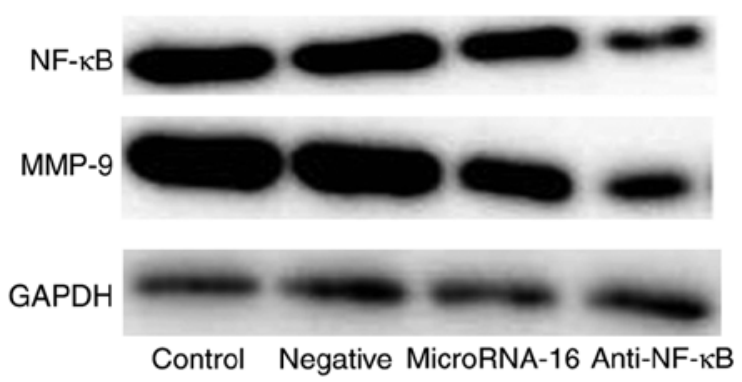

\section{B}

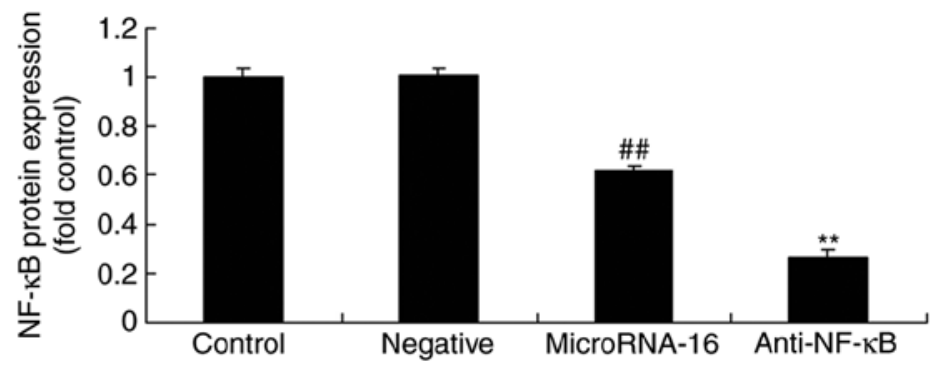

C 흠

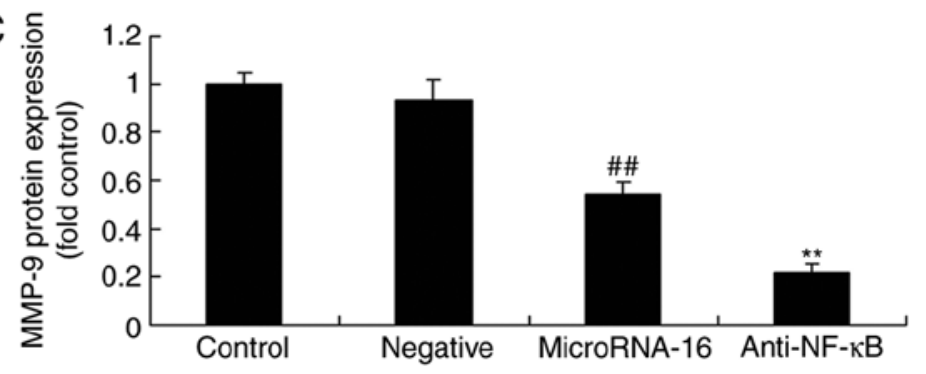

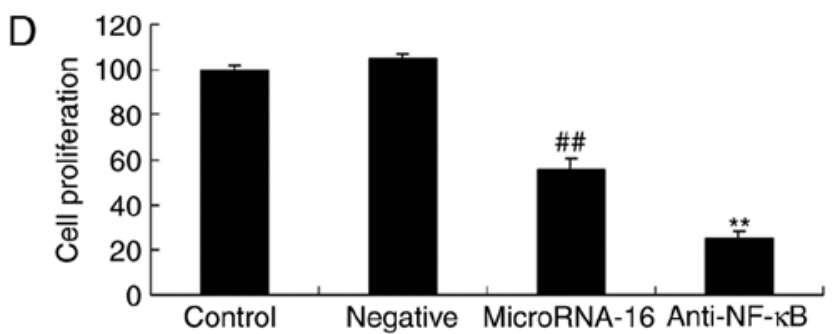
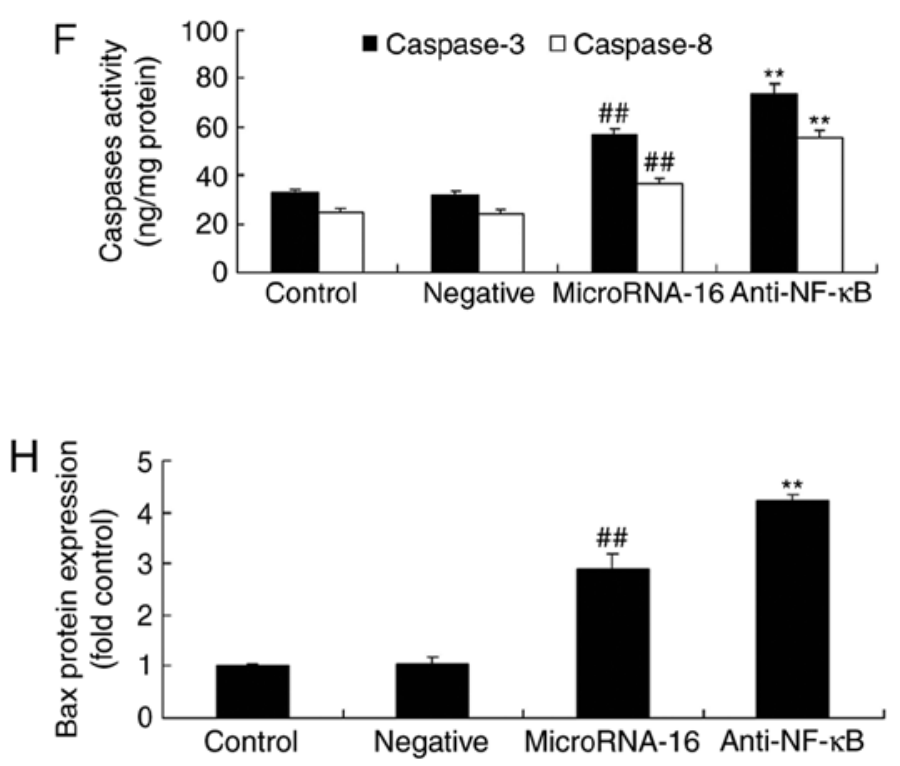
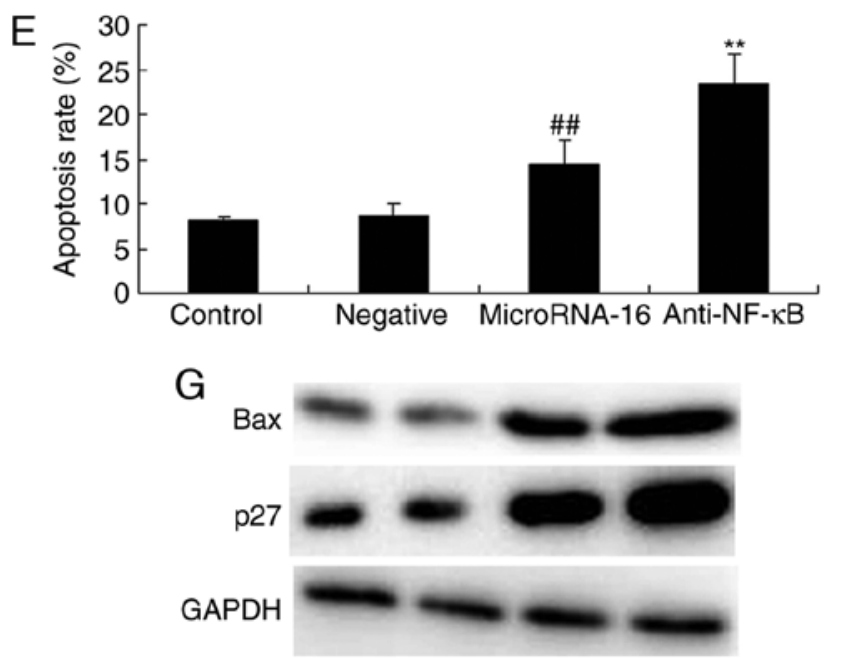

Control Negative MicroRNA-16 Anti-NF-кB

Figure 7. After NF- $\kappa \mathrm{B}$ suppression, the effects of microRNA-16 overexpression on NF- $\mathrm{B} / \mathrm{MMP}-9$ protein expression, cell proliferation and apoptosis, caspase-3/8 activities, and p27 and Bax protein expression in HP75 cells were examiend. After NF- $\mathrm{B}$ suppression, the effects of microRNA-16 overexpression on NF- $\kappa$ B and MMP-9 protein expression were examined using (A) western blot analysis and statistical analysis of (B) NF- $\mathrm{B}$ and (C) MMP-9 protein expression, (D) cell proliferation and (E) apoptosis, (F) caspase-3/8 activities, (G) p27 and Bax protein expression, determined using western blot analysis and statistical analysis of (H) Bax, and (I) p27 protein expression in HP75 cells. Control, control group. Negative, negative control group. MicroRNA-16, microRNA-16 upregulation group. Anti-NF- $\kappa \mathrm{B}, \mathrm{NF}-\kappa \mathrm{B}$ inhibitor + microRNA-16 upregulation group. Repeat times $(\mathrm{n}=3)$. ${ }^{\# \#} \mathrm{P}<0.01$ versus normal group; ${ }^{* *} \mathrm{p}<0.01$ versus microRNA-16 upregulation group.

inhibitor suppressed NF- $\mathrm{NB}$ and MMP-9 protein expression in the effects of microRNA-16 overexpression.

Effects of microRNA-16 overexpression on cell proliferation and apoptosis of HP75 cells following $N F-\kappa B$ suppression.
Then, we found that the effects of microRNA-16 overexpression on the inhibition of cell proliferation and the induction of apoptosis in HP75 cells by NF- $\mathrm{B}$ inhibitor were effectively accelerated, compared with the microRNA-16 mimics group (Fig. 7D and E). 


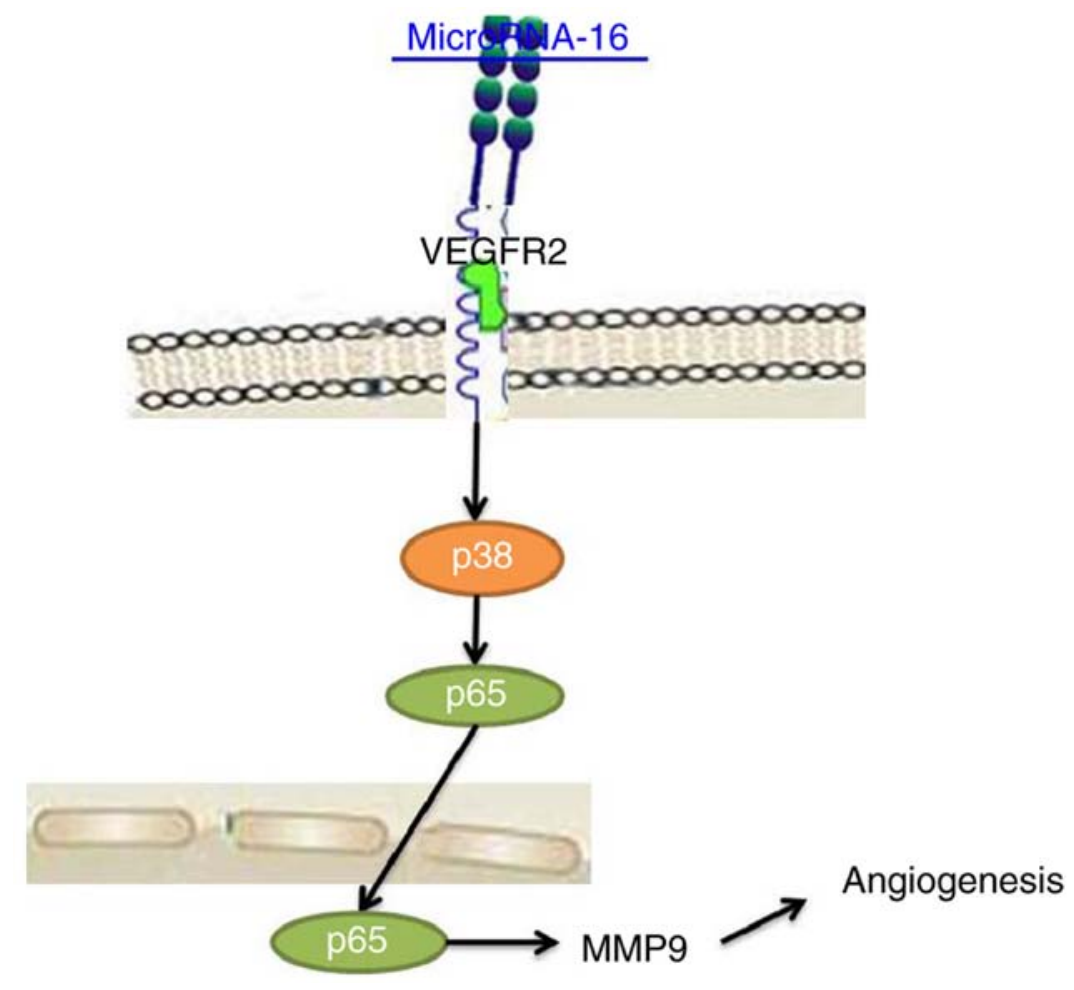

Figure 8. MicroRNA-16 expression affects the proliferation and angiogenesis of pituitary cancer through the VEGFR2/p38/NF- $\mathrm{kB}$ signaling pathway.

Effects of microRNA-16 overexpression on caspase-3/8 activities in HP75 cells following $N F-\kappa B$ suppression. However, the caspase-3/8 activities in HP75 cells following microRNA-16 overexpression in $\mathrm{NF}-\kappa \mathrm{B}$ inhibitor were higher than those of the microRNA-16 mimics group (Fig. 7F).

Effects of microRNA-16 overexpression on p27 and Bax protein expression in HP75 cells following $N F-\kappa B$ suppression. $\mathrm{NF}-\kappa \mathrm{B}$ inhibitor facilitated the effects of microRNA-16 overexpression on p27 and Bax protein expression in HP75 cells, compared with the microRNA-16 mimics group (Fig. 7G-I).

\section{Discussion}

Pituitary tumors constitute a fairly common intracranial tumor, most of which are benign. However, some secretory adenomas frequently result in endocrine diseases, including Cushing syndrome, amenorrhea and gigantism (16). Some large adenomas grow in the brain, which may compress brain tissues as a result of increased tumor volume, leading to symptoms such as visual impairment or headache. In addition, some tumors manifest certain characteristics of malignancy. For instance, some pituitary tumors grow across the sella turcica in an infiltration manner and invade the peripheral cranial structures, which may not be completely removed through surgery, and are susceptible to postoperative recurrence (17). Therefore, early diagnosis and clinical treatment of pituitary tumor is essential $(3,17)$. Our current results show that microRNA-16 expression of pituitary tumor patients was observably declined, compared with the normal group, and the high expression of microRNA-16 has longer OS and DFS in pituitary tumor patients, compared to a low microRNA-16 expression in pituitary tumor patients.
LIN-4 was identified in caenorhabditis elegans in 1993, and a large number of similar miRNAs were found in succession subsequently (18). Research regarding the relationship of miRNA with pituitary tumor has been carried out for several years, but relatively few substantial achievements have been attained. Nonetheless, the results definitely demonstrate that the pathogenesis of pituitary tumor is closely associated with the abnormal expression of miRNA (19). In the present study, the upstream microRNA-16 decreased cell proliferation and induced apoptosis of HP75 cells in a dose-dependent manner. MicroRNA-16 has been shown to sensitize breast cancer (20), ovarian cancer (21) and hepatocellular carcinoma (22) cells.

The expression of MMP-9 was significantly higher in invasive pituitary tumors than in non-invasive ones, and type IV collagen was markedly reduced in the former (9). Research suggests that in the subclass of MMPs, MMP-9 has the closest association with pituitary tumor invasion (9). The expression level of MMP-9 is notably higher in invasive pituitary tumors than in non-invasive ones, further suggesting the important role of MMP-9 in tumor invasion and metastasis (33). Therefore, MMP-9 can serve as an indicator of tumor invasion (33). Results of the present study indicated microRNA-16 upregulation significantly suppressed MMP-9 protein expression in HP75 cells. Lin et al indicated that osthole suppresses the proliferation of human glioma cells via the upregulation of microRNA-16 and downregulation of MMP-9 (23).

Tumor growth, invasion and metastasis require sufficient nutrition support, and the growth of blood vessels plays an extremely important role during this process (24). Tumor growth depends on angiogenesis, one of the essential conditions for tumor growth, invasion and metastasis (24). VEGF is a highly specific mitogen for vascular endothelial cells, which is a dimer glycoprotein with a molecular weight of 
34-46 kDa (25). VEGF can exert multiple biological effects by binding with the specific receptor on cell membrane (26). The high VEGF expression level in pituitary tumor may be one of the important factors responsible for its poor prognosis. The invasion of pituitary tumor is different from that of glioma in terms of biological behavior. The invasion of invasive pituitary tumor is associated with the expansive growth of the tumor (27). It has been suggested that VEGF can upregulate uPA expression, while uPA can activate plasmin and thus activates MMPs. Additionally, the biological behavior of invasive pituitary tumor is related to increased MMP-9 expression and the upregulated expression of angiogenesis regulatory factor VEGF (9). The new vessels promote tumor growth and invasion of the surrounding tissues. Our findings have demonstrated that microRNA-16 upregulation significantly suppressed VEGFR2 protein expression in HP75 cells. Yang et al, showed that the downregulation of microRNA-16 significantly impacted the prognosis of colorectal cancer patients by targeting VEGFR2 (28).

In recent years, great achievements have been attained in research on factors and drugs promoting tumor cell apoptosis, and research on p38MAPK has also achieved considerable progress (29). p38MAPK, which exists in a majority of cells, is a type of important signal system for eukaryotic cells to transfer extracellular signals into cells and thus induce a cell response (30). In addition to enhancing NF- $\kappa \mathrm{B}$ expression, activating $\mathrm{c}$-jun and c-fos and participating in other signal transduction, it may mainly influence cell metabolism (31). Furthermore, we found that microRNA-16 upregulation significantly suppressed p-p38MAPK and NF- $\kappa \mathrm{B}$ protein expression in HP75 cells. Chen et al reported that microRNA-16 alleviates inflammatory pain through p38 MAPK activation (32).

It is reported that, lowering the incidence of inflammationassociated liver cancer and colon cancer in mouse models results from inhibiting the activation of IKK- $\beta$-dependent $\mathrm{NF}-\kappa \mathrm{B}$. As previously indicated, the inflammatory response can activate $\mathrm{NF}-\kappa \mathrm{B}$, and the continuous activation of $\mathrm{NF}-\kappa \mathrm{B}$ can further mediate tumorigenesis (33). NF- $\kappa \mathrm{B}$ is associated with tumor invasion and metastasis. Furthermore, it can induce tumor cell apoptosis by inhibiting $\mathrm{NF}-\kappa \mathrm{B}$ activity of tumor cells, and thus inhibits tumor cell growth, as is demonstrated through experiments in vitro and in vivo (15). In-depth research has confirmed that $\mathrm{NF}-\kappa \mathrm{B}$ is closely related to some malignant solid tumors, such as pancreatic and breast cancer (15). NF- $\kappa \mathrm{B}$ activation affects the invasive and metastasis capacities of tumors, and can upregulate the expression of MMP transcription. The effect of MMPs allows for the degradation of extracellular matrix, and thus promotes tumor invasion. $\mathrm{NF}-\kappa \mathrm{B}$ inhibitor Bay 11-7082 can serve as a new research method to inhibit the NF- $\kappa \mathrm{B}$ pathway. Furthermore, it can be used to inhibit MMP expression to achieve the objective of inhibiting the invasive and metastatic capacities of tumor (13). In the present study, we found that VEGFR2 suppression reduced the effects of microRNA-16 overexpression on $\mathrm{p}-\mathrm{p} 38, \mathrm{NF}-\kappa \mathrm{B}, \mathrm{MMP}-9$ and VEGFR2 protein expression inhibition in HP75 cells. Yang et al suggested that microRNA-16 inhibits glioma cell growth and invasion through the NF- $\kappa$ B/MMP-9 signaling pathway.

Taken together, we have demonstrated that microRNA-16 expression suppressed cell proliferation, induced apoptosis and reduced angiogenesis of pituitary cancer through the VEGFR2/p38/NF- $\mathrm{BB}$ signaling pathway (Fig. 8). Therefore, microRNA-16 may be necessary for pituitary cancer via the VEGFR2/p38/NF- $\kappa$ B signaling pathway as a potential therapeutic in clinical application.

\section{References}

1. Gradiser M, Matovinovic Osvatic M, Dilber D and Bilic-Curcic I: Assessment of environmental and hereditary influence on development of pituitary tumors using dermatoglyphic traits and their potential as screening markers. Int $J$ Environ Res Public Health 13: 330, 2016.

2. Sibal L, Ugwu P, Kendall-Taylor P, Ball SG, James RA, Pearce SH, Hall K and Quinton R: Medical therapy of macroprolactinomas in males: I. Prevalence of hypopituitarism at diagnosis. II. Proportion of cases exhibiting recovery of pituitary function. Pituitary 5: 243-246, 2002.

3. Baddour HM, Lupa MD and Patel ZM: Comparing use of the Sonopet $(\circledR)$ ultrasonic bone aspirator to traditional instrumentation during the endoscopic transsphenoidal approach in pituitary tumor resection. Int Forum Allergy Rhinol 3: 588-591, 2013.

4. Robison NJ, Prabhu SP, Sun P, Chi SN, Kieran MW, Manley PE, Cohen LE, Goumnerova L, Smith ER, Scott RM, et al: Predictors of neoplastic disease in children with isolated pituitary stalk thickening. Pediatr Blood Cancer 60: 1630-1635, 2013.

5. Müssnich P, Raverot G, Jaffrain-Rea ML, Fraggetta F, Wierinckx A, Trouillas J, Fusco A and D'Angelo D: Downregulation of miR-410 targeting the cyclin $\mathrm{B} 1$ gene plays a role in pituitary gonadotroph tumors. Cell Cycle 14: 2590-2597, 2015.

6. Sivapragasam M, Rotondo F, Lloyd RV, Scheithauer BW, Cusimano M, Syro LV and Kovacs K: MicroRNAs in the human pituitary. Endocr Pathol 22: 134-143, 2011.

7. Zhao Y, Xie P and Fan H: Genomic profiling of microRNAs and proteomics reveals an early molecular alteration associated with tumorigenesis induced by MC-LR in mice. Environ Sci Technol 46: 34-41, 2012.

8. Knappe UJ, Hagel C, Lisboa BW, Wilczak W, Lüdecke DK and Saeger W: Expression of serine proteases and metalloproteinases in human pituitary adenomas and anterior pituitary lobe tissue. Acta Neuropathol 106: 471-478, 2003.

9. Liu HY, Gu WJ, Wang CZ, Ji XJ and Mu YM: Matrix metalloproteinase- 9 and -2 and tissue inhibitor of matrix metalloproteinase- 2 in invasive pituitary adenomas: A systematic review and metaanalysis of case-control trials. Medicine (Baltimore) 95: e3904, 2016.

10. Hui P, Xu X, Xu L, Hui G, Wu S and Lan Q: Expression of MMP14 in invasive pituitary adenomas: Relationship to invasion and angiogenesis. Int J Clin Exp Pathol 8: 3556-3567, 2015.

11. Escós A, Risco A, Alsina-Beauchamp D and Cuenda A: p38 $\gamma$ and p38 mitogen activated protein kinases (MAPKs), new stars in the MAPK galaxy. Front Cell Dev Biol 4: 31, 2016.

12. Liang M, Liu J, Ji H, Chen M, Zhao Y, Li S, Zhang X and Li J: A Aconitum coreanum polysaccharide fraction induces apoptosis of hepatocellular carcinoma (HCC) cells via pituitary tumor transforming gene 1 (PTTG1)-mediated suppression of the P13K/ Akt and activation of p38 MAPK signaling pathway and displays antitumor activity in vivo. Tumour Biol 36: 7085-7091, 2015.

13. Grandison L, Nolan GP and Pfaff DW: Activation of the transcription factor NF-KB in GH3 pituitary cells. Mol Cell Endocrinol 106: 9-15, 1994.

14. Lee GS, Choi KC, Han HJ and Jeung EB: The classical and a non-classical pathways associated with NF-kappaB are involved in estrogen-mediated regulation of calbindin-D9k gene in rat pituitary cells. Mol Cell Endocrinol 277: 42-50, 2007.

15. Lasa M, Gil-Araujo B, Palafox M and Aranda A: Thyroid hormone antagonizes tumor necrosis factor-alpha signaling in pituitary cells through the induction of dual specificity phosphatase 1. Mol Endocrinol 24: 412-422, 2010.

16. BuhkJH,Jung S,Psychogios MN,GörickeS,Hartz S,Schulz-Heise S, Klingebiel R, Forsting M, Brückmann H, Dörfler A, et al: Tumor volume of growth hormone-secreting pituitary adenomas during treatment with pegvisomant: A prospective multicenter study. $\mathbf{J}$ Clin Endocrinol Metab 95: 552-558, 2010.

17. Cheng JM, Gu JW, Kuang YQ, Ma Y, Xia X, Yang T, Lu M, He WQ, Sun ZY and Zhang YC: Multicenter study on adult growth hormone level in postoperative pituitary tumor patients. Cell Biochem Biophys 71: 1239-1242, 2015. 
18. Li XH, Wang EL, Zhou HM, Yoshimoto K and Qian ZR MicroRNAs in human pituitary adenomas. Int J Endocrinol 2014: 435171, 2014

19. Seltzer J, Ashton CE, Scotton TC, Pangal D, Carmichael JD and Zada G: Gene and protein expression in pituitary corticotroph adenomas: A systematic review of the literature. Neurosurg Focus 38: E17, 2015

20. Tang X, Jin L, Cao P, Cao K, Huang C, Luo Y, Ma J, Shen S, Tan M, Li X, et al: MicroRNA-16 sensitizes breast cancer cells to paclitaxel through suppression of IKBKB expression. Oncotarget 7: 23668-23683, 2016.

21. Dwivedi SK, Mustafi SB, Mangala LS, Jiang D, Pradeep S, Rodriguez-Aguayo C, Ling $\mathrm{H}$, Ivan $\mathrm{C}$, Mukherjee $\mathrm{P}$, Calin GA, et al: Therapeutic evaluation of microRNA-15a and microRNA-16 in ovarian cancer. Oncotarget 7: 15093-15104, 2016.

22. Wu WL, Wang WY, Yao WQ and Li GD: Suppressive effects of microRNA-16 on the proliferation, invasion and metastasis of hepatocellular carcinoma cells. Int J Mol Med 36: 1713-1719, 2015

23. Lin K, Gao Z, Shang B, Sui S and Fu Q: Osthole suppresses the proliferation and accelerates the apoptosis of human glioma cells via the upregulation of microRNA-16 and downregulation of MMP-9. Mol Med Rep 12: 4592-4597, 2015.

24. Ortiz LD, Syro LV, Scheithauer BW, Ersen A, Uribe H, Fadul CE, Rotondo F, Horvath E and Kovacs K: Anti-VEGF therapy in pituitary carcinoma. Pituitary 15: 445-449, 2012.

25. Fowkes RC and Vlotides G: Hypoxia-induced VEGF production 'RSUMEs' in pituitary adenomas. Endocr Relat Cancer 19: C1-C5, 2012.

26. Stepień T, Sacewicz M, Lawnicka H, Krupiński R, Komorowski J, Siejka A and Stepień H: Stimulatory effect of growth hormonereleasing hormone (GHRH(1-29)NH2) on the proliferation, VEGF and chromogranin A secretion by human neuroendocrine tumor cell line NCI-H727 in vitro. Neuropeptides 43: 397-400, 2009.
27. Sacewicz M, Lawnicka H, Siejka A, Stepień T, Krupiński R, Komorowski J and Stepień H: Inhibition of proliferation, VEGF secretion of human neuroendocrine tumor cell line NCI-H727 by an antagonist of growth hormone-releasing hormone (GH-RH) in vitro. Cancer Lett 268: 120-128, 2008.

28. Yang IP, Tsai HL, Huang CW, Lu CY, Miao ZF, Chang SF, Juo SH and Wang JY: High blood sugar levels significantly impact the prognosis of colorectal cancer patients through down-regulation of microRNA-16 by targeting Myb and VEGFR2. Oncotarget 7: 18837-18850, 2016.

29. Wang D, Wong HK, Feng YB and Zhang ZJ: 18beta-glycyrrhetinic acid induces apoptosis in pituitary adenoma cells via ROS/ MAPKs-mediated pathway. J Neurooncol 116: 221-230, 2014.

30. Peverelli E, Olgiati L, Locatelli M, Magni P, Fustini MF, Frank G, Mantovani G, Beck-Peccoz P, Spada A and Lania A: The dopamine-somatostatin chimeric compound BIM-23A760 exerts antiproliferative and cytotoxic effects in human non-functioning pituitary tumors by activating ERK1/2 and p38 pathways. Cancer Lett 288: 170-176, 2010.

31. Hoesel B and Schmid JA: The complexity of NF- $\kappa$ B signaling in inflammation and cancer. Mol Cancer 12: 86, 2013.

32. Chen W, Guo S and Wang S: MicroRNA-16 Alleviates inflammatory pain by targeting Ras-related protein 23 (RAB23) and inhibiting p38 MAPK activation. Med Sci Monit 22: 3894-3901, 2016.

33. Chen Z, Li Z, Chang Y, Ma L, Xu W, Li M, Li J, Zhang W, Sun Q, An X, et al: Relationship between NF- $\kappa$ B, MMP-9, and MICA expression in pituitary adenomas reveals a new mechanism of pituitary adenomas immune escape. Neurosci Lett 597: 77-83, 2015. 